\title{
Perancangan Aplikasi Audit Mutu Internal Pada Penerapan Sistem Penjaminan Mutu Internal (SPMI) Stmik Tasikmalaya Berbasis Web
}

\author{
Sarmidi $^{1}$ \\ ${ }^{1}$ Komputer Akuntansi STMIK Tasikmalaya, Jl RE Martadinata No. 272A Kota tasikmalaya 46151, Indonesia \\ sarmidi@stmik-tasikmalaya.ac.id ${ }^{1}$
}

\section{INFORMASI ARTIKEL}

Sejarah Artikel:

Diterima Redaksi : -

Revisi Akhir : -

Diterbitkan Online : -

\section{Kata Kunci :}

Sistem Penjaminan Mutu, Berbasis Web, UML

Korespondensi :

Telepon / Hp : +62 (0265) 556677

E-mail : sarmidi@stmik-tasikmalaya.ac.id

\section{A B S T R A K}

\begin{abstract}
Sistem Penjaminan Mutu Internal (SPMI) dipandang sebagai salah satu solusi untuk menjawab berbagai permasalahan pendidikan tinggi di Indonesia. SPMI di perguruan tinggi dimulai dengan penetapan beberapa dokumen meliputi kebijakan, standar, manual, serta dokumen formulir. STMIK Tasikmalaya sudah berupaya melaksanakan sesuai aturan SPMI yang berlaku. Hanya saja dalam pelaksanaanya tidak didukung oleh sistem informasi, sehingga proses sosialisasi dokumen tersebut belum efektif dan dapat mengakibatkan adanya keterbatasan akses bagi pihak-pihak yang membutuhkan. Aplikasi dalam bentuk website memungkinkan akses yang mudah bagi siapa saja yang berkepentingan dengan dokumen SPMI. Penelitian ini damksudkan untuk membuat aplikasi audit mutu internal SPMI yang sanag dibutuhkan oleh pihak STMIK Tasikmalaya. Dengan adanya prototipe sistem informasi penjaminan mutu ini diharapkan dapat membantu pelaksanaan proses audit dalam rangka penerapan sistem penjaminan mutu bagi pihak sekolah tinggi dalam rangka peningkatan kualitas sekolah tinggi.
\end{abstract}

\section{PENDAHULUAN}

\subsection{Latar Belakang Masalah}

Perguruan tinggi sebagai salah satu lembaga pendidikan tinggi diharapkan untuk dapat selalu menjaga dan meningkatkan mutu pendidikan yang diselenggarakan. Peningkatan mutu perguruan tinggi dapat dilakukan dengan membangun sistem penjaminan mutu perguruan tinggi yang bertujuan untuk memastikan bahwa perguruan tinggi dapat memenuhi standar nasional pendidikan tinggi (SN Dikti), sekaligus sebagai usaha memenuhi ekspektasi stakeholder terhadap proses pendidikan yang dilaksanakan.

Salah satunya yang menjadi objek penelitian penulis adalah di STMIK Tasikmalaya, yang telah melaksanakan sistem penjaminan mutunya melalui sebuah lembaga yang dikenal dengan nama Badan Penjaminan Mutu (BPM).

Pelaksanaan audit mutu internal saat ini menggunakan instrumen audit yang disusun oleh BPM berdasarkan standar dan kriteria penilaian yang digunakan BAN-PT untuk menilai perguruan tinggi. Hasil pelaksanaan audit mutu internal ini digunakan sebagai pertimbangan dalam menentukan langkah perbaikan yang diperlukan untuk meningkatkan mutu Sekolah tinggi.

STMIK Tasikmalaya dalam pelaksanaan audit mutu internal sendiri sejauh ini masih dilakukan secara manual dengan bantuan MS. Excel. Penggunaan MS. Excel adalah sebagai sarana penyimpanan data dan hasil penilaian oleh masing-masing auditor, sementara untuk pengolahan data yang terkait dengan penentuan skor untuk kriteria kuantitatif masih dihitung secara manual oleh auditee ataupun auditor. Selain itu, file Ms. Excel dari masing-masing auditor yang tersimpan pada beberapa folder dokumen yang berbeda mengharuskan staff BPM untuk merekap kembali semua data tersebut agar bisa diproses dan dianalisa untuk membuat laporan hasil audit secara keseluruhan. Pengolahan data yang masih dilakukan secara manual dan data yang belum terintegrasi ini menjadikan proses audit mutu internal yang dilaksanakan BPM menjadi kurang efisien mengingat jumlah data dan dokumen serta aktor yang terlibat dalam proses audit yang sangat banyak dan membutuhkan waktu yang relatif lama untuk menyelesaikan laporan hasil audit mutu internal. Selain itu, proses pengolahan data sebagaimana yang dilakukan saat ini juga memperbesar adanya resiko kesalahan pengolahan data. Selain itu, laporan audit yang masih berbentuk kertas dalam jumlah yang banyak menyebabkan kesulitan dalam hal penyajian dan pencarian data laporan saat dibutuhkan.

\subsection{Tujuan Dan rencana Kegiatan}

Pelaksanaan audit mutu internal merupakan salah satu kegiatan yang signifikan dalam pelaksanaan sistem penjaminan mutu internal di perguruan tinggi khususnya Sekolah Tinggi, maka BPM STMIK Tasikmalaya dirasa perlu untuk memperbaiki proses pelaksanaan audit mutu internal, salah satu caranya adalah dengan menggunakan sistem informasi berbasis web yang dapat membantu untuk mengintegrasikan data yang berasal dari banyak sumber, mempermudah pengolahan dan penyimpanan data dalam jumlah yang besar serta yang paling penting memudahkan ketersediaan informasi bagi semua pihak yang terlibat dalam proses audit mutu internal.

Audit mutu internal berbasis sistem informasi berbasis web dibutuhkan oleh BPM, tidak hanya untuk mempermudah pengolahan dan penyajian data audit, tetapi juga dapat meminimalisir biaya yang dikeluarkan dari pelakasanaan audit mutu internal secara manual. Sistem informasi audit mutu internal yang dirancang adalah sistem informasi berbasis web, mengingat kegiatan audit mutu internal yang memiliki banyak 
orang yang terlibat dan sumber data yang beragam sehingga sistem informasi berbasis web dapat mempermudah pengaksesan data dan informasi kapanpun dan dimanapun diperlukan.

Pelaksanaan Audit Mutu Internal Berbasis Web yang dirancang adalah sistem informasi yang selain membantu dalam pengolahan, penyimpanan dan penyajian data, juga diharapkan untuk mampu menyediakan informasi terkait mutu dan capaian prodi yang tidak tersedia ataupun sulit untuk diakses pada sistem yang saat ini diterapkan. Salah satu informasi yang diharapkan pengguna untuk dapat disajikan pada sistem usulan adalah data capaian prodi yang pada sistem saat ini diinputkan ke dalam excel dalam bentuk skor, sehingga BPM sendiri tidak memiliki data perkembangan capaian setiap unit yang jelas. Pengambil keputusan juga masih kesulitan untuk mendapatkan informasi terkait data capaian setiap unit.

\subsection{Tinjauan Pustaka}

Alur pelaksanaan audit pada sistem usulan secara garis besar tidak terlalu berbeda dengan sistem manual. Pada sistem Audit Mutu Internal usulan yang merupakan web based sistem, masing-masing aktor diharuskan untuk log in dan hanya dapat mengakses halaman tertentu sesuai dengan hak akses masingmasing aktor. Selain itu, terdapat beberapa aktivitas pada sistem aktual yang tidak perlu dilakukan pada sistem usulan, karena aktivitas tersebut telah digantikan oleh fungsi sistem.

1. Admin Mengelola sistem Mengelola instrument audit mutu internal

2. BPM menginputkan data unit yang berhubungan dengan pelaksanaan audit mutu internal

3. Auditor melakukan penilaian dan membuat laporan audit mutu internal per unit

4. Ketua Badan Penjaminan Mutu (BPM) mengelola instrument audit mutu internal, dan membuat laporan audit mutu internal keseluruhan.

5. Ketua unit melihat hasil audit mutu internal unit

6. Melihat hasil audit mutu internal unit Ketua BPM Melihat hasil audit mutu internal keseluruhan

\section{Metode Penelitian}

\subsection{Konsep Mutu}

Mutu merupakan sesuatu yang tidak mutlak tetapi lebih kepada apa yang dapat diterima dari sisi pelanggan, hanya saja mutu tidak hanya berdasarkan atas apa yang dibutuhkan oleh pelanggan tetapi juga berdasarkan atas apa yang pelanggan harapkan. Hal inilah yang membuat pemenuhan atas mutu sangat sulit karena hanya sedikit dari kita yang mengetahui apa yang sebenarnya kita inginkan. (Jay Schlickman, 2003:19).

Menurut ISO 9000:2000 dalam buku Hoyle (2007:10) Mutu adalah kemampuan serangkaian karakteristik yang dimiliki produk untuk memenuhi persyaratan / kebutuhan.

\subsection{Dimensi Mutu}

Menurut Garvin dalam buku Mishra (2007:24) terdapat 8 dimensi mutu yaitu :
1. Performance
: kinerja karakteristik
2. Feature
3. Reliability utama produk

\section{Reliability}

\section{Conformance}
5. Durability
6. Serviceability
7. Aesthetic
8. Preceived quality
ciri khas kinerja pada periode waktu tertentu
: keterandalan, konsistensi
: kesesuaian dengan spesifikasi umur produk kemudahan untuk diperbaiki estetika reputasi (ukuran tidak langsung karena informasi produk tidak lengkap)

\subsection{Analisa dan Perancangan Berorientasi Objek}

Tujuan dari analisa berorientasi objek adalah untuk mengembangkan sebuah model yang menggambarkan suatu perangkat lunak komputer yang dapat bekerja untuk memenuhi seperangkat persyaratan yang ditentukan oleh pengguna. Dalam membangun sebuah model analisis sama halnya seperti metode analisis konvensional, yakni membangun sebuah model analisis yang menggambarkan informasi, fungsi, dan perilaku objek. (Pressman, 2001; 572).

\subsection{UML (Unified Modelling Language)}

UML dinotasikan sebagai diagram untuk menggambarkan atau memvisualisalikan, menentukan, membangun dan mendokumentasikan aplikasi perangkat lunak. [Barclay \& Savage,2004;3]. Use case adalah teknik untuk merekam persyaratan fungsional sebuah sistem. Use case mendeskripsikan interaksi tipikal antara pada pengguna sistem dengan sistem. Setiap use case memiliki aktor utama yang meminta sistem untuk memberi sebuah layanan. Aktor utama adalah aktor dengan tujuan yang akan dipenuhi oleh use case dan biasanya adalah inisiator use case. Selain itu terdapat banyak aktor lain yang berkomunikasi dengan sistem pada saat menjalankan use case (aktor sekunder).

\subsection{Prototipe (protoype)}

Prototipe adalah suatu proses dalam membangun sebuah model yang menunjukkan fitur dari produk yang diusulkan, layanan atau sistem. Dalam membangun sebuah model yang sesuai dengan kebutuhan dasar bisnis, maka prototipe memungkinkan pengguna untuk melihat, bekerja dengan, dan mengevaluasi model dengan menyarankan perubahan pada model yang meningkatkan kemungkinan sebuah keberhasilan dari sistem yang diusulkan (Haag \& Cummings,2008;211).

Kerangka kerja penelitian menggambarkan tahapan proses yang dilakukan dalam penelitian agar penelitian dapat berjalan dengan baik dan tujuan yang 
telah ditetapkan dapat tercapai. Pada penelitian ini penulis menggunakan tahapan kerangka kerja penelitian sebagai berikut :

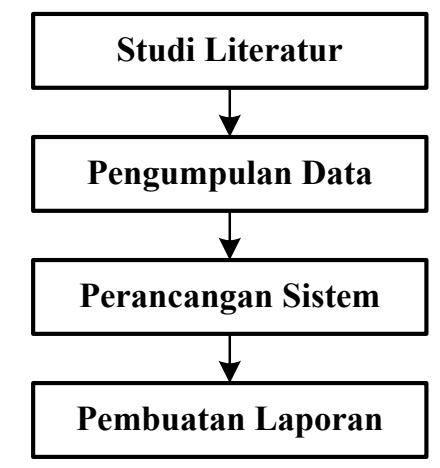

Gambar 1. Kerangka Kerja Penelitian

\subsection{Diagram Use Case}

Use case diagram digunakan untuk memodelkan fungsional sistem yang digunakan serta menggambarkan kebutuhan system dari sudut pandang user.

Berdasarkan asumsi yang digunakan dapat digambarkan diagram use case Sistem Penjaminan Mutu sebagai berikut :

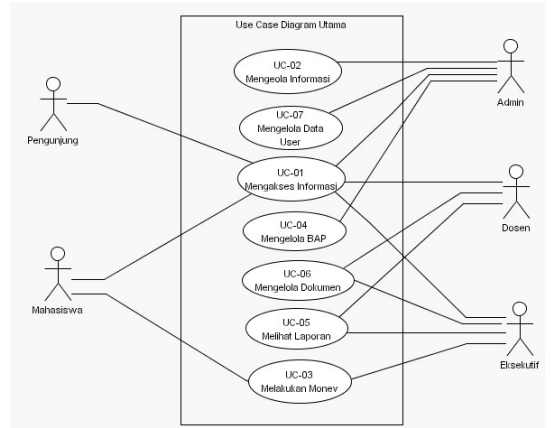

Gambar 2. Diagram Use Case Sistem Informasi Penjaminan Mutu

Berdasarkan use case diagram sistem informasi penjaminan mutu, maka use case melakukan monitoring dan evaluasi dapat diuraikan lebih terperinci sebagai berikut :

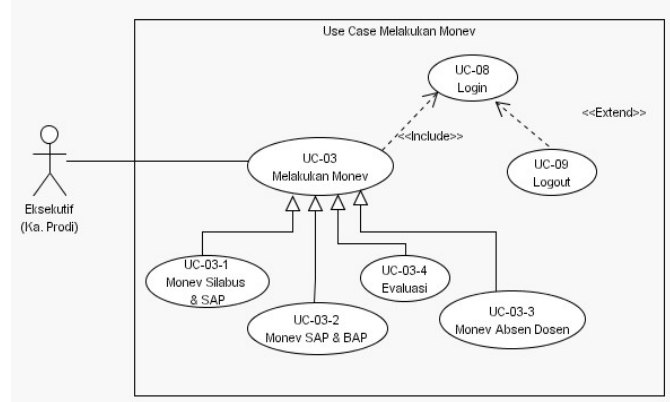

Gambar 3. Diagram Use Case Melakukan Monitoring dan Evaluasi

Berdasarkan gambar diatas, maka dapat diuraikan lebih rinci lagi mengenai use case diagram evauasi sebagai berikut :

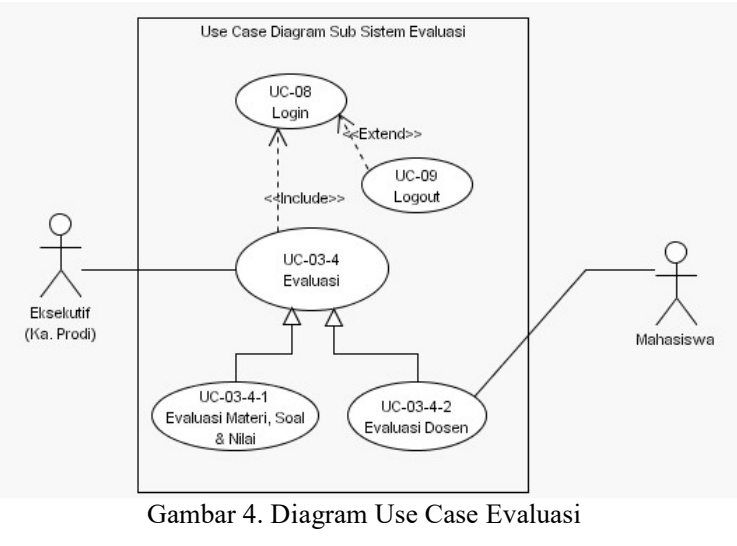

\section{HASIL DAN PEMBAHASAN}

\subsection{Rancangan Sistem}

Prototipe adalah suatu versi sistem potensial yang disediakan bagi pengembang dan calon pengguna yang dapat memberikan gambaran bagaimana kira-kira sistem tersebut akan berfungsi bila telah disusun dalam bentuk yang lengkap. Prototipe bertujuan untuk memperoleh umpan balik dari pengguna yang akan memungkinkan prototipe di ulang beberapa kali sehingga menghasilkan prototipe yang dianggap sempurna. Adapun prototipe dari sistem informasi penjaminan mutu STMIK Tasikmalaya adalah sebagai berikut :

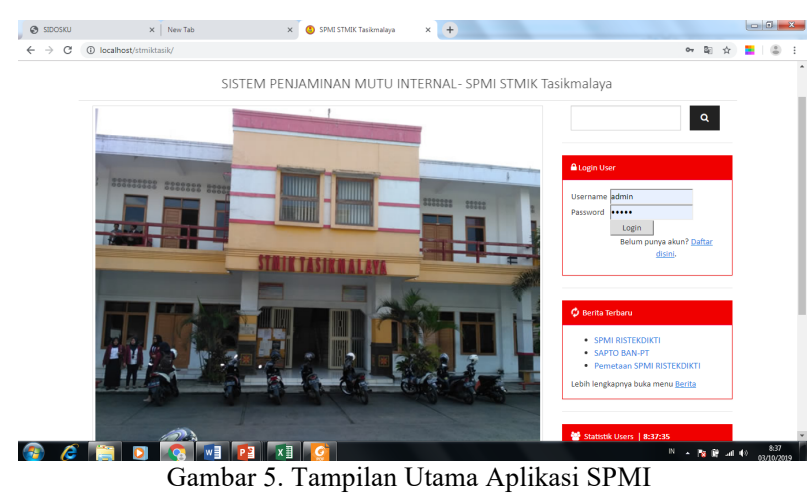

Berikut ditampilkan salah satu kegiatan Audit Mutu Internal berbasis web terhadap kepuasan mahasiswa terhadap pelayanan lembaga STMIK Tasikmalaya :

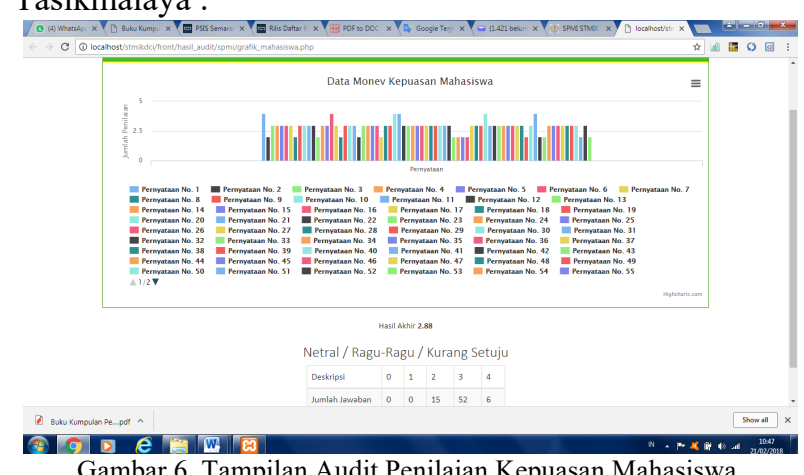




\section{Kesimpulan}

Dari perancangan sistem informasi pada BPM STMIK Tasikmalaya untuk kegiatan Audit Mutu Internal dapat ditarik kesimpulan sebagai berikut:

1. Sistem penjaminan mutu terutama pada kegiatan audit mutu di STMIK Tasikmalaya saat ini disandingkan dengan audit ISO terutama pada standar pada bidang pendidikan dan pengajaran dalam hal pelayanan kepada mahasiswa, proses sosialisasi hanya melalui rapat saja sehingga adanya keterbatasan akses bagi pihak- pihak yang membutuhkan, karena itu dibutuhkan sebuah rancangan sistem informasi berbasis web yang dapat membantu STMIK Tasikmalaya dalam menjalankan sistem penjaminan mutu tersebut.

2. Penelitian ini menghasilkan sebuah prototipe sistem informasi audit mutu pada sistem penjaminan mutu STMIK Tasikmalaya berbasis web yang dapat diimplementasikan lebih lanjut sehingga dapat membantu pelaksanaan sistem penjaminan mutu di STMIK Tasikmalaya.

\section{DAFTAR PUSTAKA}

[1] Buku Panduan Sistem Penjaminan Mutu Perguruan Tinggi (SPM-PT). Dirjen Dikti. 2010

[2] Buku Panduan Pelaksanaan Sistem Penjaminan Mutu Perguruan Tinggi (SPM-PT) Bidang Akademik. Dirjen Dikti. 2006

[3] Barclay, K \& Savage, J. 2004. Object-Oriented Design with UML and Java. United States of America : Elseiver.

[4] C. Laudon, Kenneth; \& P. Laudon, Jane. 2010. Management Information Systems :Managing The Digital Firm. Eleventh Edition.New Jersey, United States of America : Pearson Prentice Hall.

[5] Dennis, Alan; Wixom, Haley Barbara: \&Tegarden, David. 2005. Systems Analysis and Design with UML Version 2.0 : An Object-Oriented Approach.Second Edition. United States of America : John Wiley \& Sons, Inc.

[6] Dokumen SPMI STMIK Tasikmalaya 2019. 